\title{
Indicadores de desempenho do Programa Minha Casa, Minha Vida: avaliação com base na satisfação dos beneficiários
}

\author{
Performance indicators of the "Minha Casa, Minha Vida" Program: evaluation based on consumer satisfaction \\ Los indicadores de desempeño del Programa "Mi Casa, Mi Vida": Evaluación basada en la satisfacción de los \\ consumidores
}

\begin{abstract}
Resumo
0 propósito deste artigo é construir indicadores de desempenho a partir da percepção dos beneficiários do Programa Minha Casa, Minha Vida, com a utilização de recursos do Fundo de Arrendamento Residencial (PMCMV/FAR), do primeiro conjunto habitacional contratado e entregue no município de Viçosa, localizado na Zona da Mata do estado de Minas Gerais. 0 processo de avaliação seguiu cinco passos: a) resgate do desenho do Programa; b) elaboração das categorias avaliadas; c) preparação do instrumento de coleta de dados; d) pesquisa de campo; e) construção e análise dos indicadores. Verificou-se que os indicadores fornecem importantes informações sobre a realidade habitacional, o que contribui para que o PMCMV alcance seus objetivos e se aprimore.
\end{abstract}

Palavras-chave: habitação, avaliação, políticas públicas.

Vinicius de Souza Moreira - vinicius.souza@ufv.br

Doutorando em Administração, Universidade Federal de Viçosa, Departamento de Administração e Contabilidade, Viçosa, MG, Brasil.

Suely de Fátima Ramos Silveira - sramos@ufv.br

Professora Associada na Universidade Federal de Viçosa, Departamento de Administração e Contabilidade, Diretora do Instituto de Políticas Públicas e Desenvolvimento Sustentável, Viçosa, MG, Brasil.

Artigo submetido no dia 04-12-2014 e aprovado em 18-06-2015.

DOl: http://dx.doi.org/10.12660/cgpc.v20n66.41079 


\section{Abstract}

The objective of this article is to build performance indicators from the perception of the beneficiaries of the Minha Casa, Minha Vida [My House, My Life] Program with funds coming from the Fundo de Arrendamento Residencial (PMCMVIFAR) with regard to the first housing units built and delivered in Viçosa, located in the Zona da Mata region in Minas Gerais. The evaluation process followed five steps: the design of the bailout program; preparation of the categories evaluated; preparation of the data collection instrument; field research; and the construction and analysis of indicators. It was found that the indicators provide important information about the housing situation and this allows the $P M C M V$ to reach its goals and enhance itself.

Keywords: housing; evaluation; public policies.

\section{Resumen}

El objetivo de esta ponencia fue construir indicadores de desempeño desde la percepción de los beneficiarios del Programa Minha Casa, Minha Vida, con recursos del Fundo de Arrendamento Residencial (PMCMVIFAR) en las primeras viviendas contratadas y entregadas en Viçosa, ubicado en la Zona da Mata de Minas Gerais. El proceso de evaluación seguido de cinco pasos: diseño de programa de rescate; preparación de categorías evaluadas; preparación del instrumento de recolección de datos; investigacion de campo, y la construcción y análisis de los indicadores. Se encontró que los indicadores proporcionan información importante sobre la situación de la vivienda y esto permite contribuir al PMCMV a alcanzar sus metas y mejorar.

Palabras clave: vivienda; evaluación; políticas públicas.

\section{INTRODUÇÃO}

Uma das marcas do governo Lula (20032010) foi a criação de programas sociais que visavam ao atendimento de setores específicos - saúde, educação, emprego -, por exemplo, tendo como premissa a erradicação da pobreza e o desenvolvimento nacional. Dentre esse rol de iniciativas, destaca-se a criação do Programa Minha Casa, Minha Vida (PMCMV), no ano de 2009.

Esse Programa, que se tornou o carro-chefe da política habitacional do país, surgiu como uma ação anticíclica para evitar o aprofundamento da economia interna na crise do supbrime, em ebulição a partir de meados de 2008. A opção pelo setor da construção civil decorreu da possibilidade de englobar fatores que contribuem para a geração de empregos, a taxa de juros associada ao crédito imobiliário e o desenvolvimento da infraestrutura nacional (Oliveira \& Oliveira, 2012).
Nota-se, nessa perspectiva, que o PMCMV emerge como um pacote econômico direcionado à habitação de mercado. Entretanto, com a intervenção da Secretaria Nacional de Habitação de Interesse Social (SNHIS), o Programa passou a incorporar a Habitação de Interesse Social (HIS), segmento composto por famílias com rendimento mensal inferior a três salários mínimos. É nesse estrato da população que se concentra a maior parte dos brasileiros em situação de deficit habitacional: $66,6 \%$ dos 6,9 milhões de moradias na condição mais imediata de construção de novas unidades habitacionais para a solução de problemas sociais e específicos de habitação (Fundação João Pinheiro [FJP], 2014).

Ao trazer para seu escopo a HIS, quatro linhas de atuação foram desenvolvidas pelo PMCMV, das quais se destaca a modalidade com recursos do Fundo de Arrendamento Residencial (FAR), atuante em municípios com população superior a 50 mil habitantes. 
O PMCMV/FAR, por sua vez, tem o objetivo, conforme a Portaria n. 168, de 12 de abril de 2013 , de realizar a aquisição e a requalificação de imóveis destinados à alienação para famílias com renda mensal de até mil e seiscentos reais, por meio de operações feitas por instituições financeiras oficiais federais. Para cumprimento dessa finalidade, diversos são os atores envolvidos: Ministério das Cidades, Caixa Econômica Federal, Instituições Financeiras Oficiais Federais, Distrito Federal, Estados e Municípios (ou respectivos órgãos das administrações direta ou indireta) e empresas do setor da construção civil.

O padrão do provimento habitacional deve obedecer às especificações mínimas, aos valores máximos de aquisição das unidades e às orientações projetuais estabelecidas pelo Programa. Assim, as moradias devem seguir a seguinte disposição: casa com sala; dormitório para casal e dormitório para duas pessoas; cozinha; área de serviço (externa) e banheiro, totalizando, no mínimo, $36 \mathrm{~m}^{2}$.

Os conjuntos habitacionais devem ser dotados de infraestrutura urbana básica: vias de acesso e de circulação pavimentadas, drenagem pluvial, calçadas, guias e sarjetas, rede de energia elétrica e iluminação pública, rede para abastecimento de água potável, soluções para o esgotamento sanitário e coleta de lixo. As redes de energia elétrica e iluminação pública, abastecimento de água potável e as soluções para o esgotamento sanitário devem estar operantes até a data de entrega do empreendimento.

Outra indicação é que os empreendimentos habitacionais estejam inseridos na malha urbana ou em zonas de expansão urbana.
Aqueles localizados em zona de expansão devem estar contíguos à malha urbana e possuir no entorno áreas destinadas para atividades comerciais locais.

O conjunto das ações supracitadas são consequências das políticas públicas na busca por sanar o deficit habitacional do país que, pela sua realidade, requer adequada condução, evitando gastos desnecessários e desvios de rotas que possam inviabilizar a ampliação de iniciativas nesse sentido.

Por essa razão, no âmbito das políticas públicas, têm-se a análise e a avaliação de políticas, as quais são essenciais para a sociedade, uma vez que a demanda é crescente e os recursos, escassos. Embora Heller e Castro (2007) comentem sobre o reconhecimento dos pesquisadores da área de ciências sociais sobre a persistente fragilidade conceitual e metodológica para o estudo e desenvolvimento das políticas públicas, esse campo do conhecimento é apontado como importante via para debate, tanto no plano teórico quanto no metodológico (Schofield \& Suausman, 2004).

Assim, após a implementação de uma política e/ou programa, é importante verificar seus efeitos, pois, de acordo com os resultados obtidos, podem-se promover mudanças no curso ou até mesmo encerrar o ciclo de vida de determinada política. Esses efeitos podem ser mensurados pelo estabelecimento de indicadores, tendo como fonte de informações a ótica dos variados atores envolvidos nos programas.

Wu et al. (2010) argumentam que avaliação de políticas públicas pode ser direcionada a representantes governamentais ou não. To- 
davia, complementam os referidos autores que "os atores não governamentais mais importantes são, obviamente, os usuários do serviço, que têm a experiência em primeira mão de como o programa em questão está funcionando na prática" (Wu et al., 2010, p. 120). Logo, destacam-se, em especial, os beneficiários - aqueles que de fato são os experimentadores e usuários dos produtos entregues pelo PMCMV.

Diante do contexto ora apresentado, a questão da pesquisa que motivou a construção desse estudo foi: como os indicadores, fundamentados na satisfação dos beneficiários, podem auxiliar na mensuração do desempenho do Programa Minha Casa, Minha Vida com recursos FAR?

Para responder ao questionamento norteador da pesquisa, estabeleceu-se como objetivo central a construção de indicadores de desempenho a partir da percepção dos beneficiários do PMCMV/FAR do primeiro conjunto habitacional contratado e entregue no município de Viçosa, Minas Gerais.

A construção dos indicadores tangenciou os principais produtos entregues pelo Programa: a moradia, o conjunto habitacional em si e sua ligação com o entorno limítrofe ao empreendimento. Ademais, de acordo com Moares e Abiko (2006), pesquisas de satisfação e/ou percepção dos moradores dos ambientes construídos têm fundamental importância nas avaliações de pós-ocupação, pois informações essenciais sobre os projetos podem ser capturadas.

Assim sendo, justifica-se a escolha do município de Viçosa (MG) devido à facilidade em acompanhar de perto a implementação do Programa e pelo fácil acesso às famílias beneficiadas.

\section{REFERENCIAL TEÓRICO}

\subsection{Políticas públicas e programas sociais}

Tendo em vista a relevância das políticas públicas e dos programas sociais para o desenvolvimento da gestão pública, é interessante compreender os conceitos e os aspectos norteadores que permeiam essa ampla temática.

A política pública (public policy) é conceituada por diversos autores (Rua, 1997; Saravia, 2006; Souza, 2006; Dye, 2008; Matias-Pereira, 2008; Secchi, 2010). Embora existam variações entre as definições, elementos em comum podem ser destacados, sendo eles: (i) existência de um problema público; (ii) resolução pacífica de conflitos; (iii) procedimentos formais e informais; (iv) atores (agentes envolvidos); (v) ações e "não ações"; (vi) articulação e estratégia.

Portanto, a política pública é um instrumento de atuação do governo (em conjunto, ou não, com outros atores), que tem como cerne a solução não conflituosa de um problema percebido no público. Sua materialização ocorre por meio de procedimentos e regras e da proposição de linhas de atuação e programas, público-alvo, fonte de recursos, entre outros.

Simão et al. (2010) trazem um olhar complementar, tratando-a como o exercício constante do setor público com o objetivo de devolver à população as contribuições tributárias realizadas. Dessa forma, é a ação do governo buscando solucionar os problemas do país, 
como os socioeconômicos, os distributivos, ambientais e os de infraestrutura, de modo a retornar à população o valor arrecadado pelos tributos.

Um montante considerável de recursos arrecadados é destinado à implementação e à manutenção de políticas públicas. Essa alocação de recursos possibilita alcançar o desenvolvimento do país, de regiões e de municípios, pois as políticas públicas estimulam áreas essenciais para o bem-estar socioeconômico (Mattos, Teixeira \& Fontes, 2011).

Ressalta-se que a gestão pública pode utilizar diversos instrumentos para transformar as políticas públicas em ações concretas, entre as quais programas, projetos, leis e campanhas publicitárias (Mendes, Lima, Hammerschmidt, Lourenço \& Guaragni, 2010). O foco do estudo em questão são os programas sociais decorrentes do amplo rol de políticas públicas.

O programa, por sua vez, é o instrumento de organização da ação governamental para enfrentar os problemas identificados e alcançar os objetivos preteridos (Brasil, 2009). Em outras palavras, trata-se do conjunto de projetos e atividades que perseguem os mesmos objetivos (Cohen \& Franco, 2008; Morra-Imas \& Rist, 2009).

A mensuração do alcance (ou não) das iniciativas realizadas pelos programas é obtida a partir do uso ou construção de indicadores, o que traz a oportunidade de reconhecer carências e demandas socioeconômicas da população (Brasil, 2009).

Assim, o cumprimento da responsabilidade do Estado em promover o bem-estar dos cidadãos pode ser alcançado mediante a gestão governamental eficaz, que cumpra seus objetivos por meio da elaboração de políticas, programas e projetos coerentes com as necessidades da população. Nesse contexto, emerge a importância da constante avaliação dos resultados das ações governamentais, seja ela pelo acompanhamento dos processos ou pela avaliação dos impactos das políticas (Simão et al., 2010).

2.2 Avaliação: definições, características e critérios

Segundo Rossi, Lipsey e Freeman (2004), a aplicação de métodos de avaliação de programas sociais coincide com o crescimento e o aperfeiçoamento dos próprios métodos de pesquisa, bem como com as mudanças ideológicas, políticas e demográficas. Devido a esses acontecimentos, o processo avaliativo dos programas ganha notoriedade a partir da transferência de responsabilidades aos órgãos governamentais e da demanda social por respostas dos dirigentes públicos. Nessa direção, conforme indicação de Ramos e Schabbach (2012), a avaliação é uma ferramenta importante para melhorar a eficiência do gasto público, a qualidade da gestão e o controle social sobre a efetividade das ações do Estado.

Desse modo, o ato de avaliar compreende ao processo de medição sistemática da operação e/ou dos resultados de um projeto, programa ou política, em relação ao desempenho, eficácia e impacto (ambos esperados ou não) haja vista os objetivos predeterminados (implícitos ou explícitos), como forma de contribuir para o aprimoramento das ações (Morra-Imas \& Rist, 2009; Rossiet 
et al., 2004). Ao incorporar elementos valorativos e de julgamento, a avaliação passa a contemplar aspectos qualitativos, não se confundindo com o mero acompanhamento das atividades governamentais (Ramos \& Schabbach, 2012).

Portanto, a avaliação mede o desempenho com base em diferentes critérios, que podem variar de acordo com os objetivos das ações, sendo eles: eficiência, eficácia e impacto (ou efetividade) (Costa \& Castanhar, 2003).

A eficiência representa a competência para produzir resultados com gasto mínimo de recursos e esforços, e conduz, na avaliação da menor relação, o custo/benefício para o alcance dos objetivos; a eficácia está relacionada ao propósito de mensurar o grau de êxito para o alcance dos objetivos e das metas, e a efetividade (ou impacto), que é entendida como a capacidade de promover resultados (econômicos, socioculturais, institucionais e ambientais), refere-se ao aprimoramento dos objetivos (Façanha \& Marinho, 2000).

Em decorrência do momento de realização da avaliação, essa pode ser classificada como ex-ante, de processo e ex-post. A avaliação ex-ante ocorre antes de se iniciar a elaboração do programa (Cohen \& Franco, 2008), visa subsidiar o processo decisório apontando a conveniência ou não de se realizar o projeto (Cotta, 1998).

A avaliação de processo, realizada durante a execução, também denominada de gestão contínua ou monitoração, levanta informações sobre $o$ andamento do programa. $A$ avaliação ex-post, por sua vez, requer que o programa (ou uma de suas etapas) tenha sido concluído para poder ser avaliado (Costa \& Castanhar, 2003).

Davidson (2005) traça os elementos essenciais para tornar a avaliação um instrumento de ação efetivo, a saber: (i) propósito claro para a avaliação; (ii) estratégia que envolva os atores-chave; (iii) perguntas importantes e abrangentes para nortear todo o processo; (iv) respostas claras para as perguntas abrangentes.

Um dos primeiros passos da avaliação, assim como indicam Barbosa e Freitas (2012) é o resgate do desenho inicial do projeto, dos objetivos, resultados e metas. Complementam que a avaliação busca estimular a reflexão e a discussão entre diferentes atores, uma vez que um bom processo faz com que eles reflitam e aprendam entre si.

\subsection{Indicadores de desempenho}

O processo de avaliação será facilitado e mais útil se for baseado em um planejamento consistente e capaz de estabelecer relações causais, processo conhecido como cadeia de causalidade. É a factibilidade dessas relações que imprime consistência ao planejamento a ponto de a intervenção, em uma instância particular desse processo, produzir determinado efeito em certa instância mais abrangente (Costa \& Castanhar, 2003). Espera-se que todo esse processo contribua para garantir a definição clara e plausível dos objetivos do programa e a identificação de indicadores relevantes de desempenho (Cassiolato \& Gueresi, 2010).

A boa escolha de indicadores tem relação direta com o desenho do Programa. Nessa 
perspectiva, para selecionar os indicadores, é pré-requisito realizar a avaliação de adequação do objetivo do Programa, bem como saber a consistência desse objetivo quanto à capacidade de intervenção, materializada nas ações que o compõem (Brasil, 2010).

Quando criados com a finalidade de avaliar o desempenho e legitimar as políticas públicas, os indicadores são instrumentos para disponibilizar informações para a construção de diagnósticos sobre a realidade social, sendo que são elaborados não apenas para avaliar, mas também para subsidiar e amparar o desenho de determinadas políticas e programas públicos. Portanto, a construção dos indicadores dependerá do uso específico ao qual servirá e deve adequar-se àquilo que se pretende medir (Caldas \& Kayano, 2001).

Na avaliação, o indicador é a unidade que permite mensurar o alcance de um objetivo específico (Cohen \& Franco, 2008). À luz do objetivo proposto, os indicadores são os principais instrumentos para verificar se os resultados do Programa foram satisfatórios ou insatisfatórios, por isso a necessidade de defini-los em linearidade com o que se pretende entregar e alcançar (Brasil, 2010), pois eles apontam, indicam, aproximam, traduzem em termos operacionais as dimensões sociais de interesse definidas a partir de escolhas teóricas ou políticas realizadas anteriormente (Januzzi, 2005).

Os indicadores podem ser classificados como analíticos e sintéticos. $\mathrm{O}$ que os diferencia é o compromisso com a expressão analítica ou de síntese do indicador. O primeiro tipo constitui-se de medidas comumente empregadas para análise de ques- tões sociais específicas. O segundo procura sintetizar várias dimensões empíricas da realidade econômica e/ou social em uma única medida (Januzzi, 2005).

Uma das características fundamentais dos indicadores é que, necessariamente, estabelecem padrão normativo (standard) a partir do qual se avalia o estado social da realidade, construindo-se um diagnóstico que alimente o processo de definição de estratégias e prioridades, ou avalia-se o desempenho das políticas e programas, medindo-se o grau em que seus objetivos foram alcançados (eficácia), o nível de utilização de recursos (eficiência) ou as mudanças operadas no estado social da população alvo (impacto) (Banco Mundial, 1996).

De acordo com o Guia Metodológico de Indicadores de Programas, são consideradas propriedades essenciais dos indicadores: (i) validade: ter a capacidade de representar a realidade que se deseja medir; (ii) significância: dar significado ao que está sendo estudado e manter isso ao longo do tempo; (ii) confiabilidade: ter origem em fontes confiáveis, que utilizem metodologias reconhecidas e transparentes de coleta, processamento e divulgação; (iv) simplicidade: ser de fácil obtenção, construção, manutenção, comunicação e entendimento pelo público em geral (Brasil, 2010).

O indicador pode ser construído de diversas formas, de acordo com seus atributos e os aspectos que visa conhecer. No estudo em tela, a obtenção dos indicadores partiu da perspectiva dos beneficiários, ou seja, mensuraram-se os resultados do PMCMV com base na satisfação daqueles que receberam as casas. E foi justamente as respostas des- 
ses indivíduos que subsidiaram a elaboração dos indicadores. Segundo Unicef (1990) e Costa e Castanhar (2003), essa avaliação visa medir a atitude do usuário em relação à qualidade do atendimento que está obtendo do programa.

Interessante mencionar alguns estudos que utilizam a referida perspectiva para construção de indicadores de desempenho. Isto é, os beneficiários tiveram papel ativo no processo criador desse instrumento de avaliação, como é o caso dos estudos de Christopoulos, Farias e Marques (2015), Moreira, Silveira e Motter (2014) e Hernández e Velásquez (2014).

Em especial, sobre os estudos envolvendo programas e projetos habitacionais e sua relação com a percepção dos beneficiários, destacam-se as pesquisas do Instituto de Pesquisa Econômica Aplicada (Ipea, 2014), de Morais, Carneiro \& Barros Neto (2014), Schäfere Gomide (2014) e Moraes e Abiko (2006), que trazem estudos teórico-empíricos, com enfoque quantitativo e convergindo, principalmente, para pesquisas relacionadas à medição de resultados, produtos ou impactos causados por projetos executados, particularmente, pela administração pública municipal.

Diante das escolhas teóricas e conceituais ora apresentadas, os indicadores propostos por este artigo atentaram-se a medir o grau em que os objetivos do PMCMV foram alcançados, dada a satisfação dos beneficiários e tendo como premissa o desenho do Programa.

\section{PROCEDIMENTOS METODOLÓGICOS}

\subsection{Características da pesquisa}

Quanto aos fins, a pesquisa caracteriza-se como descritiva, por expor características do PMCMV/FAR para a construção dos indicadores, e como explicativa, pois buscou identificar as relações de causa e efeito que explicam a situação estudada (Cervo \& Bervian, 2002).

Quanto à natureza, a pesquisa é classificada como quantitativa, pois se caracteriza pelo emprego de quantificação tanto pelos dados coletados quanto pelo tratamento por meio de técnicas estatísticas (Richardson, 1999).

Quanto aos meios, trata-se de um estudo de caso, uma vez que permitiu o conhecimento amplo e detalhado de sua unidade de análise (Gil, 2008), isto é, os beneficiários do Conjunto Habitacional Benjamim José Cardoso, composto de 132 unidades habitacionais e localizado no município de Viçosa, região da zona Mata de Minas Gerais. O empreendimento, primeiro contratado e entregue no âmbito do PMCMV/FAR, está alocado na região periférica do município. O conjunto foi dividido em 13 quadras e 10 ruas, possui uma área de uso comum (playground) e uma área destinada à preservação ambiental.

\subsection{Etapas do processo de avaliação}

O processo de avaliação seguiu as cinco etapas indicadas na Figura 1. Além disso, trata-se de uma avaliação de resultados do tipo ex-post, pois ocorreu após a execução de todas as atividades exigidas para concluir a provisão habitacional. 


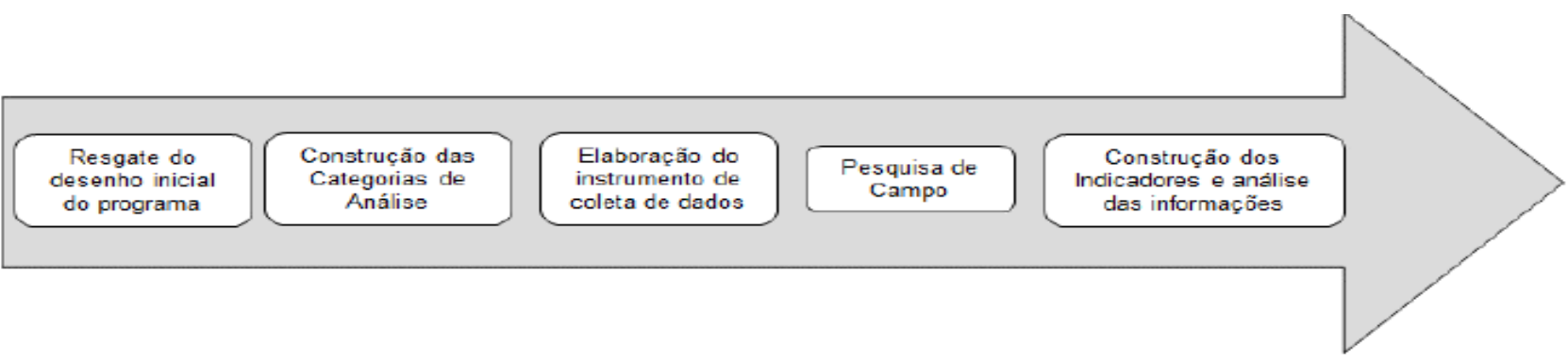

Figura 1. Estapas do Processo de Avaliação

Fonte: Elaborada pelos autores

\subsubsection{Desenho do programa}

O primeiro passo foi resgatar o desenho inicial do programa no que diz respeito a seus objetivos, metas, orientações, atividades e os produtos gerados pela intervenção. Para o cumprimento dessa etapa, analisaram-se os principais normativos (leis, portarias, especificações técnicas, cartilhas e decretos) expedidos pelo Ministério das Cidades e Caixa Econômica Federal, o agente gestor Quadro1. Documentos utilizados na pesquisa do Programa e a agente gestora do Fundo de Arrendamento Residencial, respectivamente.

No Quadro 1 estão relacionados os principais documentos utilizados. É válido destacar que os normativos consultados compreendem ao período em que o empreendimento estava sendo construído em Viçosa (MG), entre os anos de 2011 e 2013.

\begin{tabular}{|c|c|c|}
\hline DOCUMENTO & ASSUNTO & FONTE \\
\hline $\begin{array}{l}\text { Lei n. } 11.977 \text {, de } 07 \\
\text { De Julho de } 2009\end{array}$ & $\begin{array}{l}\text { Dispõe sobre o Programa Minha Casa, Minha Vida - } \\
\text { PMCMV e a regularização fundiária de assentamentos } \\
\text { localizados em áreas urbanas. }\end{array}$ & \multirow{6}{*}{$\begin{array}{l}\text { Ministério das } \\
\text { Cidades e Caixa } \\
\text { Econômica Federal }\end{array}$} \\
\hline $\begin{array}{l}\text { Lei n. } 12.424 \text {, de } 16 \\
\text { de Junho de } 2011\end{array}$ & $\begin{array}{l}\text { Altera a Lei n. } 11.977 \text {, de } 07 \text { de julho de } 2009 \text {, que } \\
\text { dispõe sobre o Programa Minha Casa, Minha Vida - } \\
\text { PMCMV e a regularização fundiária de assentamentos } \\
\text { localizados em áreas urbanas. }\end{array}$ & \\
\hline $\begin{array}{l}\text { Decreto n. } 7.499 \text {, de } \\
16 \text { de Junho De } \\
2011\end{array}$ & $\begin{array}{l}\text { Regulamenta dispositivos da Lei n. } 11.977 \text {, de } 07 \text { de } \\
\text { julho de } 2009 \text {, que dispõe sobre o Programa Minha } \\
\text { Casa, Minha Vida, e dá outras providências. }\end{array}$ & \\
\hline $\begin{array}{l}\text { Portaria n. } 465 \text {, de } 3 \\
\text { de outubro de } 2011\end{array}$ & $\begin{array}{l}\text { Dispöe sobre as diretrizes gerais para aquisição e } \\
\text { alienação de imóveis por meio da transferência ao } \\
\text { FAR, no âmbito do PNHU, integrante do Programa } \\
\text { Minha Casa, Minha Vida. }\end{array}$ & \\
\hline $\begin{array}{l}\text { Cartilha Completa } \\
\text { do Programa Minha } \\
\text { Casa, Minha Vida }\end{array}$ & $\begin{array}{l}\text { Apresenta informações gerais sobre o PMCMV. Desde } \\
\text { orientação aos beneficiários, aos gestores públicos e } \\
\text { à sociedade em geral. }\end{array}$ & \\
\hline $\begin{array}{l}\text { Termo de Adesão } \\
\text { ao Programa Minha } \\
\text { Casa, Minha Vida }\end{array}$ & $\begin{array}{l}\text { Termo que firma a parceria entre a União e o } \\
\text { Municipio que participa do Programa. Apresenta as } \\
\text { principais atribuições e compromissos que ambas as } \\
\text { partes se comprometem ao firmar o acordo. }\end{array}$ & \\
\hline
\end{tabular}

Fonte: Elaborado pelos autores 
A coleta desses dados se deu por meio de pesquisa documental. Portanto, para este estudo, o PMCMV/FAR foi tomado como dado, à luz do que ele foi formulado e implementado. Tendo em vista essas análises, apresenta-se a Figura 2 com o desenho, sumarizado, do Programa.

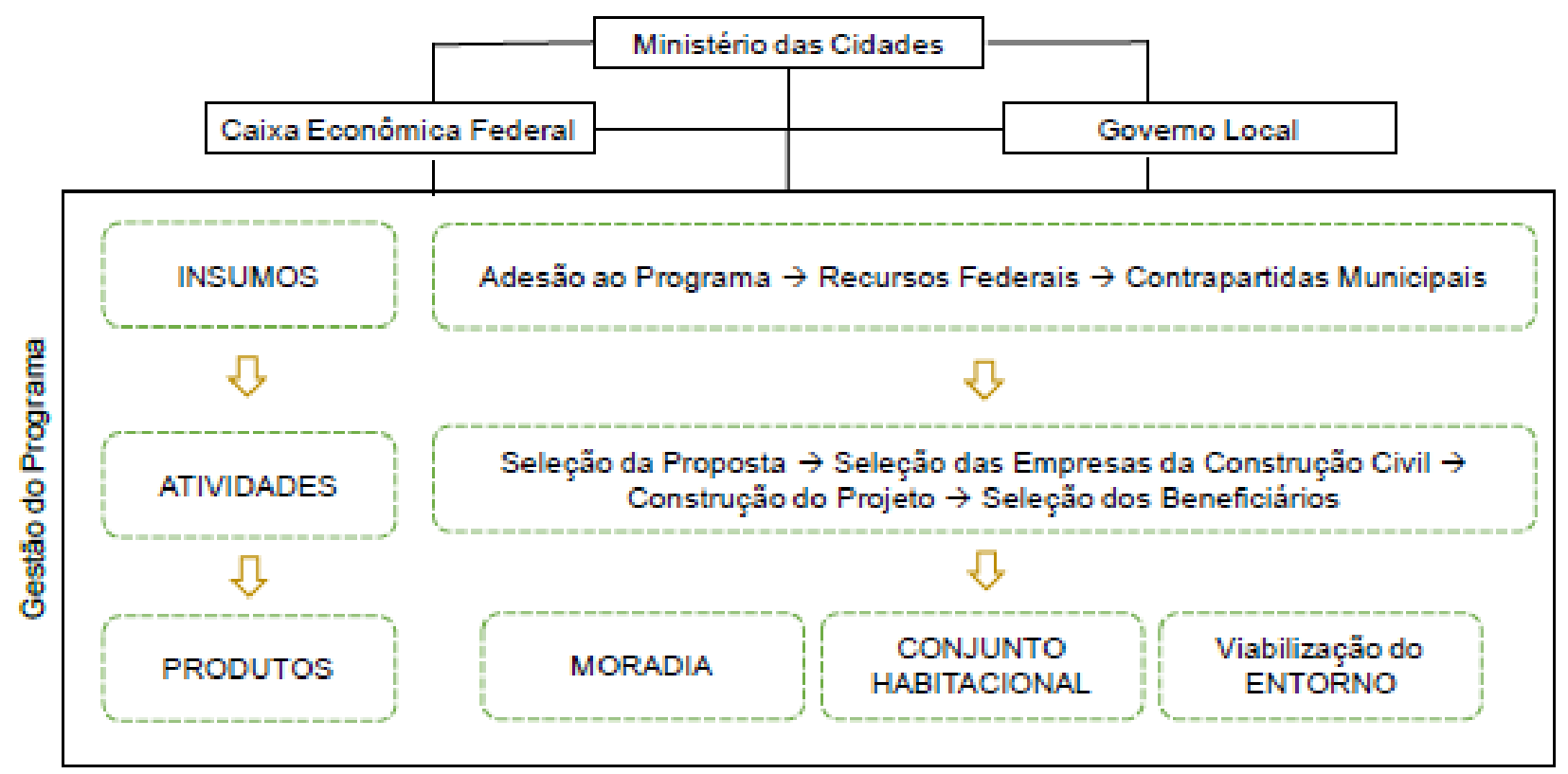

Figura 2. Desenho do Programa

Fonte: Elaborada pelos autores

O primeiro insumo considerado é a adesão do município ao Programa. A partir daí, o Governo Federal é quem subsidia a maior parte do provimento habitacional, tendo a possibilidade de o governo local aportar algum tipo de contrapartida financeiramente mensurável (a mais comum é a doação do terreno).

Esses insumos possibilitam a execução das principais atividades, por isso foram consideradas aquelas estritamente relacionadas à provisão habitacional. Com isso, foi possível sintetizar a cadeia de insumos e atividades que se congregam na entrega dos principais produtos desenhados pela intervenção.

\subsubsection{Construção das categorias analíticas}

De posse do desenho do Programa, foram determinadas as categorias de análise para avaliação da satisfação dos beneficiários. Essas dimensões englobam três principais produtos entregues pelo PMCMV: moradia, conjunto habitacional e viabilização do entorno.

A moradia representa a unidade habitacional que oferece proteção e dispõe de padrão adequado de habitabilidade: infraestrutura básica conforme as especificações estabelecidas pelo Programa. Entende-se que, em condições adequadas, a moradia contribui 
para a melhoria das condições de bem-estar, saúde e segurança da população.

O conjunto habitacional corresponde às edificações e ao grupamento de edificações de empreendimentos de interesse social. Deve se situar em terrenos que disponham (ou que sejam capazes de viabilização) de infraestrutura básica (rede pública de abastecimento de água; iluminação pública; esgotamento sanitário; drenagem pluvial, coleta de lixo, ruas e calçadas pavimentadas); possibilidade de atendimento por transporte público e proximidade de equipamentos públicos, capazes de atender à demanda prevista. Deve atender, também, conforme a tipologia do empreendimento, às especificidades dos normativos do Programa.
O entorno, por sua vez, representa as redondezas, bairros próximos e vizinhos ao empreendimento. É indicado que ele tangencie a malha urbana ou as zonas de expansão. Àqueles localizados em zona de expansão urbana devem estar contíguos à malha urbana e possuir em seus limites áreas destinadas para atividades comerciais locais.

Cada categoria foi composta por subconjuntos de itens que dão complementariedade à avaliação. No que diz respeito à moradia, foram estabelecidos os seguintes tópicos para análise: adequação ao uso familiar, qualidade da construção e segurança e conforto ambiental. O Quadro 2 traz a conceituação dos itens considerados para a elaboração da referida dimensão, bem como suas variáveis integrantes.

Quadro 2. Conceituação dos itens da categoria moradia

\begin{tabular}{|c|c|}
\hline ITEM & DESCRIÇAO \\
\hline $\begin{array}{c}\text { Adequação } \\
\text { ao Uso }\end{array}$ & $\begin{array}{l}\text { Adequação da moradia às necessidades dos beneficiários e pelo grau de atingimento } \\
\text { das características do produto. Variáveis consideradas: tamanho, disposição dos } \\
\text { cômodos e adaptação aos integrantes. }\end{array}$ \\
\hline $\begin{array}{l}\text { Qualidade } \\
\text { da } \\
\text { Construção }\end{array}$ & $\begin{array}{l}\text { Nível de qualidade (solidez e durabilidade) dos principais materiais utilizados para } \\
\text { construção da moradia. Variáveis consideradas: materiais de revestimento (pisos e } \\
\text { paredes), portas e janelas, instalações hidráulicas (tomeiras, registros e válvulas), } \\
\text { instalações elétricas, telhado e a aparência (aspecto físico da exterioridade da casa). }\end{array}$ \\
\hline Segurança & $\begin{array}{l}\text { Situação de que se sente seguro e que há o afastamento de riscos e perigos. } \\
\text { Considerou a segurança da moradia contra assaltos, roubos, invasões e vandalismo. }\end{array}$ \\
\hline $\begin{array}{l}\text { Confor } \\
\text { Ambien }\end{array}$ & $\begin{array}{l}\text { Adequação dos princípios físicos envolvidos na moradia e as necessidades do } \\
\text { ambiente. Variáveis consideradas: iluminação, ventilação; acústica (barulhos e/ou } \\
\text { ruídos), temperatura, e privacidade pessoal e de grupo familiar. }\end{array}$ \\
\hline
\end{tabular}

Fonte: Elaborado pelos autores

Em relação ao conjunto habitacional, os pontos abordados foram: qualidade da infraestrutura urbana do conjunto e qualidade dos aspectos físicos do empreendimento. No Quadro 3, descreve-se, detalhadamente, os conceitos utilizados para formar essa dimensão. 
Quadro 3. Conceituação dos itens da categoria conjunto habitacional

\begin{tabular}{|c|l|}
\hline ITEM & \multicolumn{1}{c|}{ DESCRIÇÃO } \\
\hline $\begin{array}{c}\text { Qualidade da } \\
\text { Infraestrutura } \\
\text { Urbana }\end{array}$ & $\begin{array}{l}\text { Nível de qualidade (regularidade, funcionamento, manutenção) dos } \\
\text { equipamentos e serviços urbanos que atendem às necessidades básicas do } \\
\text { Conjunto Habitacional. Variáveis consideradas: abastecimento de água, } \\
\text { esgotamento sanitário, coleta de lixo, escoamento de água, ruas e calçadas } \\
\text { (pavimentação), rede e sinal de telefonia, acessibilidade e localização. }\end{array}$ \\
$\begin{array}{c}\text { Qualidade dos } \\
\text { aspectos físicos } \\
\text { do }\end{array}$ & $\begin{array}{l}\text { Aspecto físico da exterioridade do Conjunto Habitacional. Variáveis } \\
\text { consideradas: áreas de lazer, áreas de convivência e reuniões e aparência do } \\
\text { conjunto. }\end{array}$ \\
\hline
\end{tabular}

Fonte: Elaborado pelos autores

Quanto ao entorno, tratou-se da infraestrutura, do acesso e da qualidade de serviços como subitens para avaliação da satisfação, sendo que a conceituação de cada item é apresentada no Quadro 4.

Quadro 4. Conceituação dos itens da categoria entorno

\begin{tabular}{|c|l|}
\hline ITEM & \multicolumn{1}{|c|}{ DESCRIÇÄO } \\
\hline $\begin{array}{c}\text { Qualidade } \\
\text { Infraestrutura }\end{array}$ & $\begin{array}{l}\text { Nivel de qualidade (regularidade, funcionamento, manutenção) dos principais } \\
\text { equipamentos e serviços urbanos que atendem ao entorno. Variáveis } \\
\text { consideradas: iluminação pública, ruas e calçadas (pavimentaçâ), escoamento } \\
\text { de água e praça. }\end{array}$ \\
\hline $\begin{array}{c}\text { Acesso a } \\
\text { Serviços }\end{array}$ & $\begin{array}{l}\text { Distância geográfica, tempo e custo gastos para se chegar aos principais pontos } \\
\text { da cidade e aos respectivos serviços lá prestados. Variáveis consideradas: } \\
\text { trabalho, comércio/serviços, educação, lazer, saúde, transporte público, esporte, } \\
\text { atividades culturais e assistência social. }\end{array}$ \\
\hline $\begin{array}{c}\text { Qualidade dos } \\
\text { Serviços }\end{array}$ & $\begin{array}{l}\text { Nível de qualidade (atendimento e funcionamento) dos principais serviços } \\
\text { públicos e privados disponiveis ao entorno. Variáveis consideradas: } \\
\text { comércio/serviços, educação, lazer, saúde, transporte público, esporte, } \\
\text { atividades culturais e assistência social. }\end{array}$ \\
\hline
\end{tabular}

Fonte: Elaborado pelos autores

\subsubsection{O instrumento de coleta de dados}

Definidos as categorias analíticas e os respectivos conjuntos de itens componentes da avaliação, foi construído o instrumento de coleta de dados. Optou-se pelo método survey que envolve a coleta de informações que podem variar entre crenças, opiniões, atitudes (Hair, Babin, Money \& Samuel, 2005).

O questionário foi dividido em dois blocos: o primeiro identifica o entrevistado/responsável pelo domicílio e as características de sua família. Foram arguidos: número total de habitantes na unidade, gênero, idade, escolaridade, estado civil, ocupação e rendimentos. O segundo bloco subdividiu-se em três categorias e seus subitens. Para mensurar a satisfação, as questões eram associadas a uma escala categórica de cinco pontos, onde o entrevistado tinha as opções: 1 = Péssimo, 2 = Ruim, 3 = Regular, 4 = Bom, 5 = Ótimo. Tinha-se, ainda, a opção 99 = Não soube ou não respondeu, tendo sido essa última considerada dado perdido.

\subsubsection{Pesquisa de campo}


A etapa posterior ao desenvolvimento do questionário foi a pesquisa de campo. Inicialmente, realizou-se o treinamento da equipe de coleta e a aplicação de pré-teste (questionário piloto). Durante o pré-teste, observou-se a necessidade de melhorias no instrumento de coleta relativas a incompreensão e ambiguidade das questões. Essa etapa do processo de avaliação vai ao encontro do que defendem Bisquerra, Sarriera e Martínez (2004) e Martins (2007): a construção de qualquer instrumento de medida - seja ele um questionário, teste ou outra técnica de aferição - exige a observância de cuidados, pois devem reunir requisitos mínimos para assegurar a qualidade dos dados.

Dada a adequação do instrumento de coleta de dados aos objetivos do estudo, seguiu-se para a etapa do estudo de campo, que foi realizado no mês de dezembro de 2013, sendo que os moradores do primeiro empreendimento contratado e entregue no âmbito do PMCMV/FAR na cidade de Viço- sa (MG) passaram a ocupá-lo em setembro de 2012.

O conjunto habitacional pesquisado foi construído para abrigar 132 famílias. Entretanto, a pesquisa aferiu as respostas de 100 famílias. Das 32 restantes, constatou-se que havia oito casas em situação irregular, três desocupadas e cinco estavam com os moradores inadequados devido ao repasse da unidade pelo proprietário para outras pessoas que não foram beneficiadas pelo Programa. Além disso, cinco famílias se recusaram a responder o questionário e 19 não foram encontradas durante os dias e horários visitados.

3.2.5 Construção dos Indicadores e Análise das Informações

De posse das respostas dos 100 entrevistados, procedeu-se a construção dos indicadores e daqueles sintéticos, denominados índices. Esse processo está sumarizado na Figura 3.

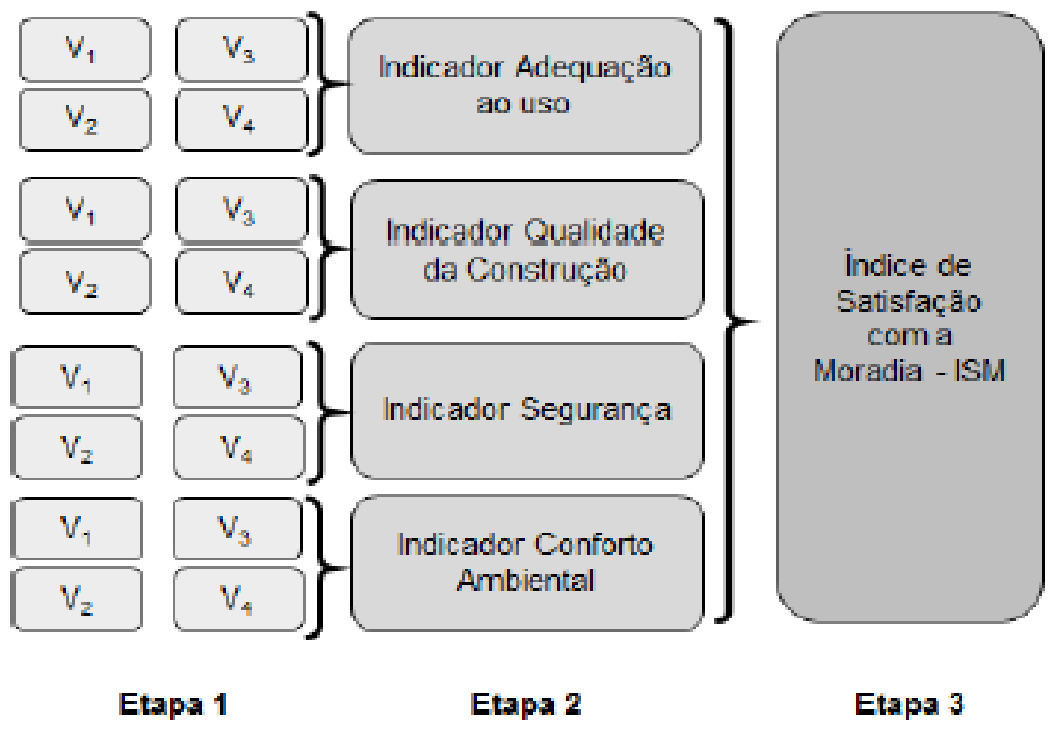

Figura 3. Exemplo da construção dos indicadores

Fonte: Elaborado pelos autores 
Cada categoria analítica possuía um conjunto de subitens composto de suas respectivas variáveis. Assim, a etapa 1 consistiu em transformar as variáveis de cada subitem em escores cujos valores variassem entre zero e um. A transformação foi realizada com base na Equação 1. Essa metodologia é utilizada no cálculo do Índice de Desenvolvimento Humano (IDH), como base nas indicações do Atlas de Desenvolvimento Humano no Brasil 2013 (Programa das Nações Unidas para o Desenvolvimento [PNUD], 2013).

$$
I_{i}=\frac{V_{i}-P v}{M v-P v}
$$

Sendo:

li - Indicador i

Vi - Valor observado do indicador i

Pv - Pior valor entre a distribuição do indicador $i$

Mv - Melhor valor entre a distribuição do indicador $i$

A Etapa 2 consistiu na construção dos indicadores. Por considerar que cada variável era essencial para a mensuração da satisfação dos beneficiários, foi atribuído o mesmo peso para todas. Assim, procedeu-se à média das variáveis. Com as médias, os indicadores foram calculados utilizando, novamente, a Equação 1.

A Etapa 3 compreendeu o estabelecimento dos indicadores sintéticos para cada categoria. Assim, três índices foram desenvolvidos (i) Índice de Satisfação com a Moradia (ISM); (ii) Índice de Satisfação com o Conjunto Habitacional (ISCH); (iii) Índice de Satisfação com o Entorno (ISE). Para compô-los, foram escolhidos os pesos atribuídos a cada indicador integrante. Para ISM, ISCH e ISE, todos os indicadores tiveram o mesmo peso, sendo o índice calculado a partir da média aritmética dos indicadores. Após o cálculo das médias, os valores foram novamente transformados pela Equação 1 para se obter o índice final que varie de 0 a 1.

Assim, a satisfação dos beneficiários foi classificada (de acordo com a definição dos autores) em grupos segundo o seguinte critério: (i) $0,00 \leq I S M$, ISCH, ISE $<0,40=$ baixo nível satisfação; (ii) $0,40 \leq$ ISM, ISCH, ISE < $0,60=$ nível regular de satisfação;(iii) $0,60 \leq$ ISM, ISCH, ISE $<0,80=$ moderado nível de satisfação; (iv) $0,80 \leq$ ISM, ISCH, ISE $\leq 1,00$ = alto nível de satisfação.

Para exame das variáveis, utilizou-se a Análise Exploratória de Dados (AED), que, segundo Triola (2005), trata-se do processo de uso de ferramentas estatísticas (gráficos, medidas de centro e medidas de variação, outliers) para investigar um conjunto de dados com o objetivo de compreender suas características.

Especificamente, fez-se uso da Estatística descritiva, que traz a média das avaliações e da Distribuição de frequência, método para agrupar dados em classes de modo a fornecer a quantidade (e/ou a percentagem) em cada classe. Com isso, pôde-se resumir e visualizar o conjunto de dados, sendo que a análise foi viabilizada por meio de procedimentos estatísticos manipulados nos programas Statistical Package for the Social Sciences (SPSS) v. 20.0® e MS Excel.

\section{RESULTADOS E DISCUSSÕES}

De modo a atender ao objetivo central do artigo, procedeu-se à construção de indicadores de desempenho a partir da percepção dos beneficiários do PMCMV/FAR sobre o primeiro conjunto habitacional contratado e entregue no município de Viçosa (MG). 
Contudo, antes apresentar os indicadores e suas discussões, menciona-se a caracterização geral dos entrevistados e de suas famílias, como forma de ilustrar os atributos do público-alvo da pesquisa.

De modo geral, os entrevistados foram mulheres $(76 \%)$, de faixa etária de 26 a 59 anos (80\%), com o 10 grau incompleto (42\%), casadas ou em união estável (51\%), exercendo atividades informais ou trabalho no $\operatorname{lar}(58 \%)$. Quanto às famílias, a maioria possuía de dois a cinco integrantes (84\%), rendimento mensal de até dois salários mínimos (97\%), com complemento de algum benefício do governo - com destaque para o Bolsa Família (80\%). Constatou-se, tam- bém, a predominância de famílias com uma ou duas crianças, no máximo dois adolescentes, um a dois adultos e sem idosos.

Sobre os indicadores, os resultados seguem a ordem "de dentro para fora," ou seja, inicialmente, analisa-se a percepção sobre a moradia ampliando o foco para o conjunto habitacional para, finalmente, avaliar a satisfação sobre o entorno.

Na Tabela 1, estão elencados os indicadores da categoria moradia. Para cada indicador, apresentam-se os resultados subdivididos nas faixas de satisfação, as frequências de indivíduos correspondentes e a média final.

Tabela 1. Indicadores da categoria moradia

\begin{tabular}{|c|c|c|c|c|}
\hline INDICADOR & INTERVALO & FREQUÉNCIA ABSOLUTA & FREQUÉNCIA RELATIVA & MÉDIA \\
\hline \multirow{5}{*}{$\begin{array}{c}\text { Adequação ao } \\
\text { Uso }\end{array}$} & $0,00 \leq$ indicador $\leq 0,39$ & 21 & $21 \%$ & \multirow{5}{*}{0,54} \\
\hline & $0,40 \leq$ indicador $\leq 0,59$ & 35 & $35 \%$ & \\
\hline & $0,60 \leq$ indicador $\leq 0,79$ & 36 & $36 \%$ & \\
\hline & $0,80 \leq$ indicador $\leq 1,00$ & 8 & $8 \%$ & \\
\hline & Total & 100 & $100 \%$ & \\
\hline \multirow{4}{*}{$\begin{array}{l}\text { Qualidade da } \\
\text { Construção }\end{array}$} & $0,00 \leq$ indicador $\leq 0,39$ & 24 & $24 \%$ & \multirow{4}{*}{0,51} \\
\hline & $0,40 \leq$ indicador $\leq 0,59$ & 41 & $41 \%$ & \\
\hline & $\begin{array}{l}0,60 \leq \text { indicador } \leq 0,79 \\
0,80 \leq \text { indicador } \leq 1.00\end{array}$ & $\begin{array}{c}30 \\
5\end{array}$ & $\begin{array}{c}30 \% \\
5 \%\end{array}$ & \\
\hline & Total & 100 & $100 \%$ & \\
\hline \multirow{5}{*}{ Segurança } & $0,00 \leq$ indicador $\leq 0,39$ & 70 & $70 \%$ & \multirow{5}{*}{0,30} \\
\hline & $0,40 \leq$ indicador $\leq 0,59$ & 10 & $10 \%$ & \\
\hline & $0,60 \leq$ indicador $\leq 0,79$ & 17 & $17 \%$ & \\
\hline & $0,80 \leq$ indicador $\leq 1,00$ & 3 & $3 \%$ & \\
\hline & Total & 100 & $100 \%$ & \\
\hline \multirow{5}{*}{$\begin{array}{l}\text { Conforto } \\
\text { Ambiental }\end{array}$} & $0,00 \leq$ indicador $\leq 0,39$ & 17 & $17 \%$ & \multirow{5}{*}{0,53} \\
\hline & $0,40 \leq$ indicador $\leq 0,59$ & 53 & $53 \%$ & \\
\hline & $0,60 \leq$ indicador $\leq 0,79$ & 29 & $29 \%$ & \\
\hline & $0,80 \leq$ indicador $\leq 1,00$ & 1 & $1 \%$ & \\
\hline & Total & 100 & $100 \%$ & \\
\hline
\end{tabular}

Fonte: Resultados da pesquisa 
Nota-se que, em relação aos aspectos físicos e construtivos do empreendimento, os indicadores adequação ao uso, qualidade da construção e conforto ambiental estiveram, em média, próximos a 0,5 ponto, o que os enquadra na faixa de nível regular quanto à satisfação. Tais resultados evidenciam que a moradia possui aspectos de sua construção que podem ser (re)adequados, uma vez que esses itens receberam avaliações regulares. Isso vai ao encontro do fato de o Programa estabelecer especificações mínimas, ou seja, o mínimo que cada unidade habitacional deve conter. Associado a isso, estabelece-se também o valor máximo de custo para as moradias. Ora, uma vez que as empresas contratadas estão inseridas na lógica de mercado, os objetivos delas tendem a ser o lucro ao menor custo. Logo, isso tem a potencialidade de contribuir para a produção de moradias com o mínimo custo possível, ou seja, apenas "dentro das especificações", o que pode, assim como no caso em tela, refletir regulares avaliações dos beneficiários.

O que nos chama mais atenção é o resultado do indicador segurança, com média 0,30 e satisfação geral baixa: $70 \%$ dos entrevis- tados avaliaram a variável com o menor grau de satisfação. O PMCMV/FAR direciona-se ao atendimento das famílias com rendimento inferior a três salários mínimos. Tais famílias, consideradas de baixa renda, são as mais expostas à vulnerabilidade social. Assim, as percepções negativas relativas à segurança contra roubos, invasões, vandalismo e violência também podem ser explicadas dada a situação de inserir diferentes famílias que não possuíam relacionamento social prévio em um novo bairro. Tal fato aumenta a possibilidade de se desenvolver patologias sociais, como gangs e crime organizado, por justamente inexistirem as relações afetivas de vizinhança. Reforça-se que pessoas, com valores e costumes peculiares, têm maior propensão à criação de conflitos, o que pode influenciar no sentimento de insegurança por parte dos beneficiários.

Na Tabela 2, sintetizam-se os resultados dos indicadores de desempenho específicos à unidade habitacional e é apresentado o Índice de Satisfação com a Moradia (ISM). A proposta é mensurar a satisfação, de modo geral, com a casa entregue pelo PMCMV/ FAR.

Tabela 2. Índice de Satisfação com a Moradia (ISM)

\begin{tabular}{l|c|c|c}
\hline INTERVALO - ISM & FREQUÉNCIA ABSOLUTA & FREQUÉNCIA RELATIVA & MÉDIA \\
\hline $0,00 \leq$ ISM $\leq 0,39$ & 42 & $42 \%$ & \\
\hline $0,40 \leq$ ISM $\leq 0,59$ & 37 & $37 \%$ & \multirow{2}{*}{0,44} \\
\hline $0,60 \leq$ ISM $\leq 0,79$ & 16 & $16 \%$ & \\
\hline $0,80 \leq$ ISM $\leq 1,00$ & 5 & $100 \%$ & \\
\hline Total & 100 & $100 \%$ & \\
\hline
\end{tabular}

Fonte: Resultados da pesquisa 
Constata-se que a média do ISM indicou satisfação regular $(0,44)$ por parte dos beneficiários. A maioria figurou-se na faixa de baixa avaliação e a minoria na satisfação elevada. Esses resultados mostram que, para o caso estudado, a moradia não atendeu satisfatoriamente aos anseios de seus beneficiários, um resultado intrigante, pois trata-se do principal produto entregue pelo Programa.

Não se considera que o PMCMV tenha provido habitações de baixa qualidade ou inadequadas à habitabilidade, outrora, acredita-se que deva haver mais espaços que deem a oportunidade da realização de consultas prévias aos futuros moradores. Tal comentário vai na direção de não ter sido encontrado nos normativos, vigentes à época de contratação do empreendimento analisado, a abertura para a participação social no processo decisório do Programa. Nessa perspectiva, a avaliação nos remonta a aspectos que tangenciam a formulação/ implementação do Programa. Os desafios dizem respeito a como abrir e/ou ampliar os canais de participação cidadã no âmbito do PMCMV/FAR, perpassando por pontos desde a capacitação para participar até a sua efetivação enquanto exigência.

Salienta-se, ainda, que, por se tratar de um programa federal, descentralizado aos estados e municípios, e que possui aparato institucional já desenvolvido, considera-se importante alinhar a avaliação dos beneficiários com as avaliações técnicas para, de fato, analisar a qualidade das moradias produzidas e se, necessário, promover alterações no curso das intervenções. Outro aspecto quanto ao processo avaliativo é a sua realização por órgãos independentes, isto é, desvinculados do governo, uma vez que somente representantes da Caixa Econômica Federal realizam essa atividade (normalmente por meio de vistorias).

Convidado, agora, a avaliar "o lado de fora de sua casa", apresentam-se os resultados da satisfação dos beneficiários quanto ao conjunto habitacional. As informações constam na Tabela 3.

Tabela 3. Indicadores da categoria conjunto habitacional

\begin{tabular}{c|c|c|c|c}
\hline INDICADOR & INTERVALO & FREQUÉNCIA ABSOLUTA & FREQUÉNCIA RELATIVA & MÉDIA \\
\hline \multirow{3}{*}{$\begin{array}{c}\text { Qualidade da } \\
\text { Infraestrutura }\end{array}$} & $0,00 \leq$ indicador $\leq 0,39$ & 5 & $5 \%$ & \\
\cline { 2 - 4 } Urbana do & $0,40 \leq$ indicador $\leq 0,59$ & 21 & $21 \%$ & \multirow{3}{*}{0,68} \\
Conjunto & $0,60 \leq$ indicador $\leq 0,79$ & 51 & $51 \%$ & \\
\cline { 2 - 4 } & $0,80 \leq$ indicador $\leq 1,00$ & 23 & $100 \%$ & \\
\cline { 2 - 4 } & Total & 100 & $37 \%$ & \multirow{2}{*}{0,52} \\
\hline \multirow{3}{*}{$\begin{array}{c}\text { Qualidade dos } \\
\text { Aspetos Físicos }\end{array}$ do Conjunto } & $0,00 \leq$ indicador $\leq 0,39$ & 37 & $16 \%$ & \\
\cline { 2 - 5 } & $0,40 \leq$ indicador $\leq 0,59$ & 26 & $21 \%$ & \\
\cline { 2 - 5 } & $0,60 \leq$ indicador $\leq 0,79$ & 16 & $100 \%$ & \\
\cline { 2 - 5 } & $0,80 \leq$ indicador $\leq 1,00$ & 21 & & \\
\cline { 2 - 5 } & Total & 100 & & \\
\hline
\end{tabular}

Fonte: Resultados da pesquisa 
O indicador qualidade da infraestrutura urbana do conjunto diz respeito aos aspectos urbanos e habitacionais que são essenciais à habitabilidade do conjunto, como abastecimento de água, saneamento básico e distribuição de energia. Observa-se que a média de avaliações foi 0,68, traduzindo moderado nível de satisfação dos beneficiários. Interessante notar que $51 \%$ estiveram na faixa moderada e $23 \%$ no alto nível de satisfação. Nota-se, com isso, que tais aspectos atenderam em média, com nível moderado-alto, às necessidades dos beneficiários.

A qualidade dos aspectos físicos do conjunto refere-se às construções e/ou edifica- ções que são exigidas pelos normativos e que devem integrar o conjunto habitacional. Denominam-se áreas de uso comum espaços de lazer, reuniões e calçadas. Identificou-se que a média apontou moderado nível de satisfação $(0,52)$, sendo que essa variável dividiu as opiniões dos beneficiários: embora $37 \%$ indicaram baixa satisfação, $16 \%$ avaliaram moderadamente e $21 \%$ apresentaram elevada satisfação.

Ao sintetizar os resultados dos indicadores de desempenho específicos à ao conjunto habitacional, obteve-se o Índice de Satisfação com o Conjunto Habitacional (ISCH), apresentando na Tabela 4.

Tabela 4. Índice de Satisfação com o Conjunto Habitacional - ISCH

\begin{tabular}{l|c|c|c|}
\hline INTERVALO - ISCH & FREQUÉNCIA ABSOLUTA & FREQUÉNCIA RELATIVA & MÉDIA \\
\hline $0,00 \leq I S C H \leq 0,39$ & 10 & $10 \%$ & \\
\hline $0,40 \leq I S C H \leq 0,59$ & 42 & $42 \%$ & \multirow{2}{*}{0,61} \\
\hline $0,60 \leq I S C H \leq 0,79$ & 29 & $29 \%$ & \\
\hline $0,80 \leq I S C H \leq 1,00$ & 19 & $19 \%$ & \\
\hline Total & 100 & $100 \%$ & \\
\hline
\end{tabular}

Fonte: Resultados da pesquisa

Verifica-se que o ISCH refletiu, em média, moderada satisfação $(0,61)$ dos beneficiários com reduzido percentual (10\%) de indivíduos situados no baixo nível de satisfação. Isso nos sugere que os moradores do Conjunto Habitacional Benjamim José Cardoso apresentaram nível mediano de satisfação quanto aos aspectos físicos e de infraestrutura do empreendimento, que são exigências mínimas contidas nos normativos. Salienta-se, todavia, que o interessante seria que as satisfações se concentrassem nas faixas superiores de análise, fato que não foi constatado. Isso nos mostra que, no caso estudado, os beneficiários não se sentiram com as expectativas superadas no que diz respeito ao conjunto habitacional, o que nos remete, mais uma vez, à lógica de mercado, na qual as empresas contratadas para construção dos projetos se inserem.

Ampliando um pouco mais a visão sobre "o lado de fora de sua casa", são apresentados os resultados da satisfação dos beneficiários quanto ao Entorno. Tais informações estão dispostas na Tabela 5. 
Tabela 5. Indicadores da categoria entorno

\begin{tabular}{|c|c|c|c|c|}
\hline INDICADOR & INTERVALO & FREQUÊNCIA ABSOLUTA & FREQUĖNCIA RELATIVA & MÉDIA \\
\hline \multirow{5}{*}{$\begin{array}{l}\text { Infraestrutura } \\
\text { do Entorno }\end{array}$} & $0,00 \leq$ indicador $\leq 0,39$ & 28 & $28 \%$ & \multirow{5}{*}{0,50} \\
\hline & $0,40 \leq$ indicador $\leq 0,59$ & 46 & $46 \%$ & \\
\hline & $0,60 \leq$ indicador $\leq 0,79$ & 13 & $13 \%$ & \\
\hline & $0,80 \leq$ indicador $\leq 1,00$ & 13 & $13 \%$ & \\
\hline & Total & 100 & $100 \%$ & \\
\hline \multirow{5}{*}{$\begin{array}{l}\text { Acesso a } \\
\text { Serviços }\end{array}$} & $0,00 \leq$ indicador $\leq 0,39$ & 44 & $44 \%$ & \multirow{5}{*}{0,46} \\
\hline & $0,40 \leq$ indicador $\leq 0,59$ & 25 & $25 \%$ & \\
\hline & $0,60 \leq$ indicador $\leq 0,79$ & 27 & $27 \%$ & \\
\hline & $0,80 \leq$ indicador $\leq 1,00$ & 4 & $4 \%$ & \\
\hline & Total & 100 & $100 \%$ & \\
\hline \multirow{5}{*}{$\begin{array}{c}\text { Qualidade dos } \\
\text { Serviços }\end{array}$} & $0,00 \leq$ indicador $\leq 0,39$ & 21 & $21 \%$ & \multirow{5}{*}{0,56} \\
\hline & $0,40 \leq$ indicador $\leq 0,59$ & 32 & $32 \%$ & \\
\hline & $0,60 \leq$ indicador $\leq 0,79$ & 34 & $34 \%$ & \\
\hline & $0,80 \leq$ indicador $\leq 1,00$ & 13 & $13 \%$ & \\
\hline & Total & 100 & $100 \%$ & \\
\hline
\end{tabular}

Fonte: Resultados da pesquisa

A viabilização do entorno, entre os principais produtos entregues pela intervenção, é o menos palpável e aquele mais afastado da visão de posse sobre a casa. Entretanto, trata-se de uma categoria importante, pois visa avaliar a satisfação quanto às regiões limítrofes ao conjunto habitacional para verificar se o Programa atende às recomendações de construir o empreendimento integrado à cidade.

Os três indicadores dessa categoria analítica figuraram-se, em média, na faixa de satisfação regular, sendo que o indicador acesso a serviços obteve a menor pontua- ção $(0,46)$. Os resultados nos mostram que o entorno que abriga o conjunto para a maioria dos beneficiários possui infraestrutura pouco adequada e não Ihes proporciona facilidade em acessar aos principais serviços ofertados pela cidade (tanto públicos quanto privados). Aos serviços, que são passíveis de acesso, a satisfação quanto à qualidade é vista como regular.

De modo a sintetizar os indicadores de desempenho específicos ao entorno, calculou-se o Índice de Satisfação com o Entorno (ISE), conforme os resultados apresentados na Tabela 6. 
Tabela 6. Índice de Satisfação com o Entorno (ISE)

\begin{tabular}{l|c|c|c|}
\hline Intervalo - ISE & Frequência Absoluta & Frequência Relativa & Média \\
\hline $0,00 \leq \mathrm{ISE}<0,40$ & 34 & $34 \%$ & \\
\hline $0,40 \leq \mathrm{ISE}<0,60$ & 32 & $32 \%$ & \multirow{2}{*}{0,50} \\
\hline $0,60 \leq \mathrm{ISE}<0,80$ & 28 & $28 \%$ & \\
\hline $0,80 \leq \mathrm{ISE} \leq 1,00$ & 6 & $6 \%$ & \\
\hline Total & 100 & $100 \%$ & \\
\hline
\end{tabular}

Fonte: Resultados da pesquisa

Visualiza-se que a média de satisfações $(0,50)$ atingiu a faixa regular, sendo que a maioria apresentou baixa satisfação (34\%) e a minoria elevada (6\%). Ao observar os dados agregados pelo ISE, chama-se atenção para questões como a segregação do espaço urbano quando se trata da provisão habitacional para população de baixa renda. $A$ partir da perspectiva dos beneficiários, por intermédio de sua avaliação de satisfação, a construção do empreendimento pouco contemplou os elementos utilizados para mensurar o relacionamento moradia-conjunto-cidade.

Ao analisar a transversalidade das satisfações entre as três categorias analisadas, observa-se que a avaliação sobre o ponto de vista dos beneficiários nos permite observar pontos críticos e que merecem atenção dos atores envolvidos no Programa, como segurança, acesso a serviços e infraestrutura do entorno.

Convém, por tais razões, ressaltar que diversos empecilhos são observados para a construção desses conjuntos, sendo a falta de terras urbanas um dos mais recorrentes. Por isso, empreendimentos de HIS tendem a ser alocados em locais distantes (regiões periféricas, em sua maioria) das principais áreas urbanas, como é o caso do Conjunto Habitacional Benjamim José Cardoso. Por conseguinte, uma série de questões é remontada, como a demarcação de áreas para interesse social, e o empenho do município com a questão habitacional. Esses aspectos tangenciam o fato da existência, atuação e do grau de aderência da gestão pública local às suas especificações.

Ao pensar nessas questões, olhares e atenções direcionam-se ao Plano Diretor, ao Plano Local de Habitação de Interesse Social (PLHIS) e aos Conselhos Municipais de Habitação (CMH), que representam instrumentos e arenas decisórias de fundamental importância para a gestão e o planejamento das políticas urbanas, entre as quais se insere a temática habitacional.

\section{CONSIDERAÇÕES FINAIS}

O presente artigo buscou responder como os indicadores, fundamentados na satisfação dos beneficiários, podem auxiliar na mensuração do desempenho do Programa Minha Casa, Minha Vida com recursos do Fundo de Arrendamento Residencial. Para tanto, tomou-se como objeto de estudo o primeiro conjunto contratado e entregue no município de Viçosa (MG). 
Portanto, com base no desenho do Programa, três categorias de análise foram estabelecidas: moradia, conjunto habitacional e entorno. Em vista disso, foi possível perceber que a construção de indicadores é um recurso metodológico útil e capaz de auxiliar na avaliação dos programas sociais, em especial, os de habitação. A metodologia aqui empregada configura-se como um recurso parcimonioso devido à facilidade para a coleta de informações, cálculo e compreensão dos resultados.

Verificou-se, ainda, que os indicadores fornecem importantes informações sobre a realidade habitacional e isso contribui para que o PMCMV alcance seus objetivos e se aprimore, desde que acompanhados e inseridos em um sistema maior de monitoramento e avaliação.

Reforça-se, nessa perspectiva, a relevância dos estudos avaliativos para a área de políticas públicas. Quando eles são realizados com enfoque para subsidiar decisões a respeito da continuidade, aperfeiçoamento e responsabilização dos agentes, configuram-se como valiosa ferramenta de gestão e, quando o intuito é informar aos usuários e/ou beneficiários e à sociedade em geral sobre seu desempenho e impactos, lança-se mão de um instrumento essencial de accountability.

Por fim, considera-se pertinente também a incorporação da percepção dos beneficiários no processo de avaliação, pois julga-se de fundamental importância consultar aqueles que de fato usufruem dos produtos entregues e vivenciam seus resultados e implicações. Todavia, convém que se- jam realizadas avaliações comparativas, de modo a triangular os pontos de vista dos demais atores envolvidos no PMCMV/FAR para que se possa proporcionar um estudo mais amplo e que dê voz a todos os responsáveis pelo provimento habitacional à população de interesse social.

\section{REFERÊNCIAS}

Banco Mundial (1996). Designing Project Monitoring and Evaluation. Washington: World Bank, Operations Evaluation Department, 1996. Recuperado em 3 janeiro, 2013, de www.worldbank.org.

Barbosa, R. de P., \& Freitras, G. K. (2012). Avaliação da iniciativa água e clima, uma parceria HSBC-WWF. In: A Relevância da avaliação para o investimento social privado. Organização Fundação Itaú Social, Fundação Roberto Marinho, Move. São Paulo: Fundação Santillana.

Bisquerra, R., Sarriera, J. C., \& Martínez F. (2004). Introdução à estatística. Porto Alegre: Artmed.

Brasil (2010). Ministério do Planejamento. Secretaria de Planejamento e Investimentos Estratégicos. Indicadores de Programas, Guia estratégico.

Brasil. (2009). Manual de apresentação de estudos de viabilidade de projetos de grande vulto. Ministério do Planejamento, Orçamento e Gestão. Secretaria de Planejamento e Investimentos Estratégicos, Brasília.

Caldas, E. de L., \& Kayano, J. (2001). Indicadores para o Diálogo. São Paulo: Instituto Pólis, PGPC-EAESP-FGV, CEDEC. Recupe- 
rado em 3 janeiro, 2013, de http://www.polis. org.br.

Cassiolato, M., \& Guerese S. (2010). Como elaborar Modelo Lógico: roteiro para formular programas e organizar avaliação. IPEA Nota Técnica n. 6. Brasília.

Cervo, A. L., \& Bervian, P. A. (2002). Metodologia Científica. São Paulo: McGraw-Hill do Brasil.

Christopoulos, T. P., Farias, L. E. G., \& Marques T. C. A. (2015). Evaluating Banking Agents: A case of Brazilian Banking Correspondents. Dlsu Business \& Economics Review, 24(2), 92-107.

Cohen, E., \& Franco, R. (2008). Avaliação de projetos sociais. Petrópolis: Vozes.

Costa, F. L., \& Castanhar, J. C. (2003). Avaliação de programas públicos: desafios conceituais e metodológicos. Rio de Janeiro: Revista de Administração Pública, 37(5), 969-992.

Cotta, T. C. (1998) Metodologias de avaliação de programas e projetos sociais: análise de resultados e de impactos. Revista do Serviço Público, Ano 49, n. 2, pp. 103-124.

Davidson, E. J. (2012). Tornar as avaliações estrategicamente práticas e relevantes. In: A Relevância da avaliação para o investimento social privado. Organização Fundação Itaú Social, Fundação Roberto Marinho, Move. São Paulo: Fundação Santillana.

Dye, T. R. (2008).Understanding public policy. Pearson Education, Inc. Upper Saddle River, New Jersey.12th ed.
Façanha, L. O., \& Marinho, A. (2000). Programas sociais: efetividade, eficiência e eficácia como dimensões operacionais de avaliação. IPEA e Instituto de Economia (IE) - Texto para discussão, 445 - versão revisada.

Fundação João Pinheiro. (2014). Centro de Estatísticas e Informações. Deficit habitacional no Brasil 2011-2012: resultados preliminares. Fundação João Pinheiro. Centro de Estatísticas e Informações. Belo Horizonte.

Gil, A. C. (2008). Métodos e técnicas de pesquisa social. 6a ed. São Paulo: Atlas.

Hair, J. F., Babin, B., Money, A. H., \& Samuel, P. (2005). Fundamentos de métodos de pesquisa em administração. Porto Alegre: Bookman.

Heller L.,\& Castro, J. E. (2007). Política pública de saneamento: apontamentos teóricos conceituais. Engenharia Sanitária e Ambiental, 12(3).

Hernández, G., \& Velásquez, S. (2014). Vivienda y calidad de vida: medicióndel hábitat social enel México Occidental. Bitácora, 24(1), 149-200.

Instituto de Pesquisa Econômica Aplicada (2014). Pesquisa de Satisfação dos Beneficiários do Programa Minha Casa Minha Vida. Recuperado em 5 maio, 2015, de http:// hdl.handle.net/11058/3298.

Jannuzzi, P. M. (2005). Indicadores para diagnóstico, monitoramento e avaliação de programas sociais no Brasil. Revista do Serviço Público, 56(2), 137-160. 
Martins, G. A. (2007). Sobre Confiabilidade e Validade. Revista Brasileira de Gestão de Negócios, p. 820, n. 7.

Matias-Pereira, J. (2008). Manual de Gestão Pública Contemporânea. 7a ed. São Paulo: Atlas.

Mattos, L. B., Teixeira, E. C., \& Fontes, R. M. O. (2011). Políticas Públicas e desenvolvimento. Viçosa, MG: UFV/DER/DEE.

Mendes, A. M. C. P., Lima, J. E. S., Hammerschmidt, K. S. A., Lourenço, M. S., \& Guaragni, M. V. (2010). Políticas públicas, desenvolvimento e as transformações do Estado brasileiro. In: Silva, C. L., \& Lima, J. E. S. (orgs). Políticas públicas e indicadores para o desenvolvimento sustentável. pp. 3-34. São Paulo: Saraiva.

Moraes, O. B, \& Abiko, A. K (2006). Utilização da análise fatorial para a identificação de estruturas de interdependência de variáveis em estudos de avaliação pós-ocupação. In: XI Encontro Nacional de Tecnologia no Ambiente Construído. Anais... Florianópolis.

Morais, M. V, Arneiro, T. M., \& Barros Neto, J. de P. (2014). Projeto de habitação de interesse social: satisfação do usuário final. Anais... Recuperado em 5 maio, 2015, de http://www.infohab.org.br/entac2014/artigos/paper_621.pdf.

Moreira, V. S., Silveira, S. F. R., \& Motter, K. Z. (2014). Avaliação de impacto do Pronaf B sobre a satisfação de agricultores familiares em municípios de Minas Gerais. EstudosSociedade e Agricultura, 22(2), 432-456.
Morra-Imas, L. G., \& Rist, R. C. (2009). The road to results: designing and conducting effective development evaluations. The World Bank.

Oliveira, V. F., \& Oliveira, E. P. A. Q. (2012). O papel da Construção Civil na organização do espaço e do desenvolvimento regional. The 4st International Congress on University-Industry Coorporation. Anais... Taubaté, São Paulo.

Programa das Nações Unidas para o Desenvolvimento. (2013). Atlas do desenvolvimento humano no Brasil 2013. Recuperado em 28 abril, 2014, de http://www.pnud.org.br/atlas.

Ramos, M. P., \& Schabbach, L. M. (2012). O estado da arte da avaliação de políticas públicas: conceituação e exemplos de avaliação no Brasil. Revista de Administração Pública, 46(5):1271-294.

Richardson, R. J. (1999). Pesquisa Social: métodos e técnicas. 3. ed. São Paulo.

Rossi, P. H., Lipsey, M. W., \& Freeman, H. E. (2004). Evaluation: a systematic approach.

Rua, M G. (1997). Análise de políticas públicas: conceitos básicos. Brasília: ENAP.

Santos, A. M. C. (1991). Sociabilidade e ajuda mútua na periferia urbana de Viçosa, Minas Gerais. 1991. 351p. Dissertação de mestrado em Extensão Rural, Universidade Federal de Viçosa, Departamento de Economia Rural, Viçosa (MG).

Saravia, E. (2006). Introdução à Teoria da Política Pública. Brasília: ENAP. 
Schafer, E. F., \& Gomide, F. P. B. (2014). Avaliação Pós-Ocupação do conjunto habitacional Moradias União Ferroviária Bolsão Audi/ União, Curitiba (PR). EngenhariaSanitária e Ambiental, 19(2).

Schofield, J., \& Sausman, C. (204) Symposium on implementng public policy: learning from theory and practice introducing. Recuperado em 10 setembro, 2013, de http:// www3.interscience.wiley.com.

Secchi, L. (2010). Políticas públicas: conceitos, esquemas de análise, casos práticos. São Paulo: Cengage Learning.

Silva, M. O. S. (2008). Avaliação de políticas e programas sociais: uma reflexão sobre o conteúdo teórico e metodológico da pesquisa avaliativa. In: Silva, M. O. S. (Org.) Pesquisa avaliativa: aspectos teórico-metodológicos. São Paulo: Veras Editora.

Simão, A. G., Silva, C. L., Silva, H. P., Castanheira, M. A. V., Jurec, P. S. S. \& Wiens, S. (2010). Indicadores, políticas públicas e a sustentabilidade. In: SILVA, C. L; LIMA, J. E. S. (orgs). pp. 35-54 Políticas públicas e indicadores para o desenvolvimento sustentável. São Paulo: Saraiva.

Souza, C. (2006). Políticas Públicas: uma revisão da literatura. Sociologias, Porto Alegre, ano 8(16), 20-45.

Unicef. (1990). Guide for monitoring and evaluation. New York. 